\title{
Improvement of Oxygen Saturation Levels is Associated with Response to Adaptive Servo- Ventilation Therapy in Heart Failure Patients
}

Toshimitsu Kato, Noriaki Takama and Masahiko Kurabayashi

Department of Cardiovascular Medicine, Gunma University School of Medicine, Maebashi, Japan

Correspondence should be addressed to: Toshimitsu Kato; kotobuki_604@yahoo.co.jp

Received Date: 10 November 2013; Accepted Date: 17 January 2014; Published Date: 28 February 2014

Academic Editor: Luís V. Martínez-Dolz

Copyright (C) 2014 Toshimitsu Kato, Noriaki Takama and Masahiko Kurabayashi. Distributed under Creative Commons CC-BY 3.0

\begin{abstract}
Although adaptive servo-ventilation (ASV) therapy is considered clinically beneficial to patients with heart failure (HF), a large proportion of patients fail to show improvement in HF. We aimed to identify reliable markers indicative of a favorable response to ASV.

We evaluated 103 consecutive patients with New York Heart Association (NYHA) class II-IV HF who were scheduled for ASV therapy for 3 months. Patients were classified as responders if their brain natriuretic peptide levels were decreased after 3 months.

Twenty-one patients (20.3\%) failed to respond to ASV. No significant differences were observed between responders and nonresponders with regard to NYHA classification, age, gender, body mass index, drug therapy, and cardiovascular risk factors. Polysomnography showed no significant baseline differences between the 2 groups in the apnea-hypopnea index (AHI) and percent sleep time of oxygen saturation level below 90\% (responders, 4.7\% \pm 9.2\%; nonresponders, $3.7 \% \pm 6.0 \% ; P=0.68$ ). The percent sleep time of oxygen saturation level below $90 \%$ is similar parameter as cumulative percentage of time at a pulse-oximetry oxygen saturation below 90\% (CT90\%) which is measured by in-home screening. We named it "Modified CT90\%". After ASV therapy for 3 months, NYHA classification remarkably improved in responder group. Logistic regression analysis revealed that improvement of modified CT90\%<1 was independent factor for the responder group. The adjusted odds ratio was 0.685 (95\% confident interval $0.485-0.967, P=0.03$ ).
\end{abstract}

Our study suggests that improvement of modified CT $90 \%<1$ at 3 months is associated with a favorable response to ASV therapy.

Keywords: Heart failure, Adaptive Servo-Ventilation Therapy, Responder, Nonresponder.

\section{Introduction}

Adaptive servo-ventilation (ASV) is designed specifically to treat all forms of central sleep apneas (CSA), including complex and mixed sleep apnea (Teschler et al., 2001). Sleep-disordered breathing (SDB) is closely related not only to heart

Cite this Article as: Toshimitsu Kato, Noriaki Takama and Masahiko Kurabayashi (2013), "Improvement of Oxygen Saturation Levels is Associated with Response to Adaptive Servo-Ventilation Therapy in Heart Failure Patients," JMED Research, Vol. 2014 (2014), Article ID 188674, DOI: 10.5171/2014.188674 
failure (HF) (Pepperll et al., 2003) (Kasai et al., 2006) (Arzt et al., 2008) but also to cardiovascular diseases, including hypertension, fatal arrhythmias, and coronary artery disease (Javaheri et al., 1998) (Moruzzi et al., 1999) (Ben-Dov et al., 2007) (Wang et al., 2007) (Serizawa et al., 2008) (Somers et al., 2008) (Takama and Kurabayashi, 2009). Furthermore, SDB is a strong risk factor for fatal cardiovascular events and mortality (Takama and Kurabayashi, 2007) (Kato et al., 2009). Therefore, SDB needs to be treated to stabilize the underlying cardiovascular disease. Most patients with cardiovascular disease suffer not only from CSA but also from other types of SDB such as obstructive sleep apnea (OSA) and hypopnea. ASV effectively treats CSA and Cheyne-Stokes respiration (CSR) and also other types of SDB including OSA and complex sleep apnea syndrome. It offers the added advantage of providing expiratory positive airway pressure and a pressure support system (Egea et al., 2008). ASV treatment reduces the risk of life-threatening events in HF patients thus demonstrating that ASV is an effective option for treating HF (Tanaka and Kurabayashi, 2012).

Despite the demonstrated clinical benefits of ASV therapy in HF patients, a substantial proportion of patients failed to show improvement in HF in response to ASV. Therefore, we aimed to identify reliable factors indicative of a positive response to ASV.

\section{Materials and Methods}

\section{Study Design and Ethics}

This was a retrospective, observational study. A total of 103 consecutive HF patients who were hospitalized for the first time with class II-IV symptons, as defined by the New York Heart Association (NYHA) classification of HF stages, underwent fullnight polysomnography (PSG) after medical therapy was optimized. ASV was initiated in the hospital after patients had undergone PSG. ASV treatment was recommended regardless of SDB severity and type (Takama and Kurabayashi, 2011).
All procedures were performed at the Department of Cardiovascular Medicine, Gunma University Hospital. Outpatient visits were used to follow up. We measured BNP levels just before starting ASV therapy and after ASV therapy for 3 months. Based on previous studies indicating that decreased levels of brain natriuretic peptide (BNP) correlated significantly with clinical improvement (Clerico and Emdin, 2004) (Doust et al., 2005), patients were classified as responders if their BNP levels decreased after 3 months and as nonresponders if their BNP levels did not decrease. We also performed PSG after ASV therapy for 3 months.

This study was conducted in accordance with the recommendations of the Declaration of Helsinki (1975), and the protocol was approved by the medical center's Institutional Review Board. Informed consent was provided by all patients before participating in the study.

\section{Sleep Evaluation and Treatment Devices}

PSG was performed using digital polygraphy (E-Series Plus; Compumedics, Abbotsford, Victoria, Australia). We evaluate sleep architecture such as sleep stages, arousals, apnea, and hypopnea by electroencephalography,

electrooculography, chin electromyography, chest and abdominal movements, airflow, arterial oxygen saturation.

"Percent sleep time of oxygen saturation level below 90\%" which is evaluated by PSG is similar parameter as cumulative percent of time at a pulse-oximetry oxygen saturation below 90\% (CT90\%) which is evaluated by in-home screening. We named it "Modified CT90\%". The difference between the two parameter is "total sleep time" in case of modified CT90\%, "total study time" in case of CT90\%.

ASV device was an AutoSet-CS (ResMed, Sydney, Australia) with a full facemask (ResMed). ASV provides 4-cm $\mathrm{H}_{2} \mathrm{O}$ expiratory positive airway pressure and a suitable minimum-maximum inspiratory support, which was within the range of 3-8 
$\mathrm{cmH}_{2} \mathrm{O}$. The backup respiratory rate was 15 breaths/min.

\section{Statistical Analysis}

2-tailed $\mathrm{t}$ test was performed to compare continuous data. Chi-squared test was performed to compare categorical data. Univariate and multivariate analysis were performed using logistic regression analysis. Significance level was set at $<5 \%$. All statistical analyses were performed with EZR (Saitama Medical Center, Jichi Medical University), which is a graphical user interface for R (The R Foundation for Statistical Computing, Vienna, Austria, version 2.15.3). More precisely, it is a modified version of $\mathrm{R}$ commander (version 1.6-3) designed to add statistical functions frequently used in biostatistics.

\section{Results}

The study group consisted of $103 \mathrm{HF}$ patients (age, $70 \pm 11$ years; 66 males, 37 females). All patients were treated with ASV after medical treatment was optimized in the acute phase. The patients were classified into 2 groups: responders were 82 patients who showed decreased BNP levels after 3 months of ASV therapy, whereas nonresponders were 21 patients whose BNP levels did not improve after 3 months of ASV therapy.

Baseline BNP levels were high for the 2 groups (responders, $590 \pm 591 \mathrm{pg} / \mathrm{mL}$; nonresponders, $412 \pm 622 \mathrm{pg} / \mathrm{mL} ; P=$ 0.25). Baseline left ventricular ejection fraction (LVEF) before ASV therapy was low for the 2 groups (responders, $41.9 \% \pm$ $18.3 \%$; nonresponders, $49.3 \% \pm 15.0 \%$; $P=$ 0.07). No significant differences were observed between the 2 groups with respect to age, gender, body mass index, drug therapy, or cardiovascular risk factors, including a history of hypertension, dyslipidemia, diabetes mellitus, metabolic syndrome, underlying cardiac disease, and chronic kidney disease. Blood gas analysis also showed no significant difference between the groups. Table 1 presents the baseline characteristics of patients. 


\begin{tabular}{|c|c|c|c|}
\hline & $\begin{array}{c}\text { Responders } \\
(n=82)\end{array}$ & $\begin{array}{l}\text { Nonresponders } \\
\qquad(n=21)\end{array}$ & P value \\
\hline$B N P(p g / m L)$ & $590 \pm 591$ & $412 \pm 622$ & 0.25 \\
\hline NYHAIII, IV (\%) & $36(43.9)$ & $10(47.6)$ & 0.80 \\
\hline Age (years) & $69 \pm 11$ & $74 \pm 9$ & 0.09 \\
\hline Male(\%) & $54(66)$ & $15(71)$ & 0.63 \\
\hline Body mass inde $\times\left(\mathrm{kg}^{2} / \mathrm{m}\right)$ & $24.8 \pm 6.2$ & $24.3 \pm 4.5$ & 0.75 \\
\hline \multicolumn{4}{|l|}{ Blood pressure $(\mathrm{mmHg})$} \\
\hline Systolic & $128 \pm 19$ & $122 \pm 21$ & 0.33 \\
\hline Diastolic & $70 \pm 11$ & $71 \pm 13$ & 0.75 \\
\hline \multicolumn{4}{|l|}{ Drug therapy $(\%)$} \\
\hline B-blocker & $22(26.8)$ & $4(19.0)$ & 0.78 \\
\hline ARBS or ACE inhibitors & $52(63.4)$ & $9(42.9)$ & 0.23 \\
\hline Diuretics & $54(65.8)$ & $11(52.4)$ & 0.59 \\
\hline \multicolumn{4}{|c|}{ Cardiovascular risk factors (\%) } \\
\hline Hypertension & $59(72.0)$ & $13(61.9)$ & 0.36 \\
\hline Dyslipiderna & $48(58.5)$ & $10(47.6)$ & 0.69 \\
\hline Diabetes mellitus & $25(30.5)$ & $9(42.9)$ & 0.38 \\
\hline Metabolic syndrome & $22(26.8)$ & $4(19.0)$ & 0.98 \\
\hline Chronic kdny disease & $8(9.8)$ & $1(4.8)$ & 0.18 \\
\hline \multicolumn{4}{|l|}{ Underlying dise ase (\%) } \\
\hline Ischemic Heart Dis ease & $36(46.3)$ & $11(52.4)$ & 0.48 \\
\hline Valvular Heart Disease & $9(11.0)$ & $3(14.3)$ & 0.68 \\
\hline Gardiomyopathy & $30(36.6)$ & $3(14.3)$ & 0.05 \\
\hline Others & $7(6.1)$ & $4(19.0)$ & 0.32 \\
\hline \multicolumn{4}{|l|}{ Echocardiography } \\
\hline LAdiameter(mm) & $42.5 \pm 8.7$ & $40.4 \pm 10.9$ & 0.59 \\
\hline LVEF $(\%)$ & $41.9 \pm 18.3$ & $49.3 \pm 15.0$ & 0.07 \\
\hline \multicolumn{4}{|l|}{ Bloodgas analysis ( $\mathrm{mmHg}$ ) } \\
\hline Arterial $\mathrm{O}_{2}$ tension & $88.3 \pm 21.6$ & $94.5 \pm 25.7$ & 0.34 \\
\hline Arterial $\mathrm{CO}_{2}$ tension & $37.2 \pm 4.4$ & $37.5 \pm 5.0$ & 0.84 \\
\hline
\end{tabular}

Data given as mean $\pm \mathrm{SD}$ or $\mathrm{n}(\%)$.

BNP, brain natriuretic pept ide; ARB, angiotensin II receptor blocker; ACE, angiotensin I-converting enzyme; LA, left atrium; LVEF, left ventricular ejection fraction, LVEF calculated using Simpson method.

On full-night PSG, no significant differences were observed with respect to AHI (responders, $26.7 \pm 15.3 / \mathrm{h}$; nonresponders, $32.2 \pm 16.7 / \mathrm{h} ; P=0.41)$, CSA index, OSA index, mixed apnea index (AI), hypopnea index (HI), sleep efficiency, sleep stages, baseline oxygen saturation level, minimum oxygen saturation level, oxygen desaturation index at the $4 \%$ level (4\%ODI), and modified CT90\% (responders, $4.7 \% \pm 9.2 \%$; nonresponders, $3.7 \% \pm 6.0 \% ; \quad P=0.68$ ). Table 2 summarizes several parameters analyzed during PSG. 


\begin{tabular}{|c|c|c|c|}
\hline & $\begin{array}{l}\text { Responders } \\
\quad(n=82)\end{array}$ & $\begin{array}{l}\text { Nonresponders } \\
\qquad(n=21)\end{array}$ & P value \\
\hline Apnea hypopnea index(/h) & $26.7 \pm 15.3$ & $32.2 \pm 16.7$ & 0.18 \\
\hline Central apnea index (/h) & $7.7 \pm 11.1$ & $6.1 \pm 8.6$ & 0.56 \\
\hline Obstructive apnea index(/h) & $3.9 \pm 5.8$ & $7.9 \pm 11.1$ & 0.16 \\
\hline Mixed apnea index(/h) & $1.1 \pm 2.4$ & $3.6 \pm 6.7$ & 0.13 \\
\hline Hypopnea index(/h) & $13.5 \pm 10.3$ & $14.7 \pm 11.1$ & 0.68 \\
\hline Sleep efficiency $(\%)$ & $45.4 \pm 19.6$ & $38.2 \pm 18.3$ & 0.16 \\
\hline NREM stage I (\%) & $33.7 \pm 24.9$ & $40.7 \pm 27.8$ & 0.30 \\
\hline NREM stage II (\%) & $49.7 \pm 22.1$ & $48.7 \pm 27.8$ & 0.87 \\
\hline NREM stage III (\%) & $4.6 \pm 7.8$ & $5.2 \pm 8.4$ & 0.79 \\
\hline NREM stage IV(\%) & $0.8 \pm 1.9$ & $0.3 \pm 0.8$ & 0.36 \\
\hline REM(\%) & $10.7 \pm 12.1$ & $5.0 \pm 6.2$ & 0.07 \\
\hline Baseline oxygen saturation level(\%) & $96.0 \pm 1.8$ & $96.1 \pm 1.9$ & 0.89 \\
\hline Minimum oxygen saturation level (\%) & $83.6 \pm 6.7$ & $84.9 \pm 6.0$ & 0.45 \\
\hline $4 \% \mathrm{ODI}(/ \mathrm{h})$ & $25.0 \pm 16.7$ & $23.5 \pm 17.5$ & 0.75 \\
\hline Modified CT90\% & $4.7 \pm 9.2$ & $3.7 \pm 6.0$ & 0.68 \\
\hline \multicolumn{4}{|c|}{$\begin{array}{l}\text { Data given as mean } \pm \text { SD. } \\
\text { NREM, nonrapid eye movement; REM, rapid eye movement; ODI, oxygen } \\
\text { desaturation index; CT90\%, cumulative percentage of time at a pulse-oxymetry } \\
\text { oxygen saturation below } 90 \% \text {. }\end{array}$} \\
\hline
\end{tabular}

In responders (Table 3), sleep efficiency did not significantly improve after ASV therapy, but significant improvement were observed with respect to NYHA classification, LVEF (before ASV therapy, 41.9\% \pm 18.3\%; after ASV therapy, 46.9\% \pm $15.8 \% ; P=0.01$ ), atrial $\mathrm{O}_{2}$ tension (blood gas analysis), AHI (before ASV therapy,
$42.9 \pm 25.7 / \mathrm{h}$; after ASV therapy, $16.5 \pm$ $14.9 / \mathrm{h} ; P=0.01$ ), CSA index, OSA index, mixed AI, HI, baseline oxygen saturation level, minimum oxygen saturation level, 4\%ODI, and modified CT90\% (before ASV therapy, $4.7 \% \pm 9.2 \%$; after ASV therapy, $0.46 \% \pm 1.2 \% ; P=0.01$ ). 


\begin{tabular}{|c|c|c|c|}
\hline & Before ASV therapy & After ASV therapy & $P$ value \\
\hline$B N P(p g / m L)$ & $590 \pm 591.5$ & $250.9 \pm 360.0$ & $0.01^{*}$ \\
\hline NHYAIII IV(\%) & $36(43.9)$ & $21(25.6)$ & $0.02^{*}$ \\
\hline $\operatorname{LVEF}(\%)$ & $41.9 \pm 18.3$ & $46.9 \pm 15.8$ & $0.01^{*}$ \\
\hline Arterial $\mathrm{O}_{2}$ tension $(\mathrm{mmHg})$ & $88.3 \pm 21.6$ & $97 \pm 20.6$ & $0.03^{*}$ \\
\hline Arterial $\mathrm{CO}_{2}$ tension $(\mathrm{mmHg})$ & $37.2 \pm 4.4$ & $37.6 \pm 4.4$ & 0.11 \\
\hline Apnea hypopnea index $(/ \mathrm{h})$ & $26.7 \pm 15.3$ & $6.2 \pm 6.6$ & $0.01^{*}$ \\
\hline Central sleep apnea index $(/ \mathrm{h})$ & $7.7 \pm 11.1$ & $0.06 \pm 0.17$ & $0.01^{*}$ \\
\hline Obstructive sleep apnea index $(/ \mathrm{h})$ & $3.9 \pm 5.8$ & $1.1 \pm 2.3$ & $0.01^{*}$ \\
\hline Mixed apnea index $(/ \mathrm{h})$ & $1.1 \pm 2.4$ & $0.04 \pm 0.19$ & $0.01^{*}$ \\
\hline Hypopnea index $(/ \mathrm{h})$ & $13.5 \pm 10.3$ & $4.9 \pm 5.4$ & $0.01^{*}$ \\
\hline Sleep efficiency(\%) & $45.4 \pm 19.6$ & $45.8 \pm 17.9$ & 0.62 \\
\hline NREM stage I (\%) & $33.7 \pm 24.9$ & $25.8 \pm 19.5$ & 0.13 \\
\hline NREM stage II (\%) & $49.7 \pm 22.1$ & $58.6 \pm 18.6$ & 0.07 \\
\hline NREM stage III (\%) & $4.6 \pm 7.8$ & $4.1 \pm 5.8$ & 0.27 \\
\hline NREM stage IV (\%) & $0.8 \pm 1.9$ & $0.88 \pm 2.4$ & 0.95 \\
\hline $\operatorname{REM}(\%)$ & $10.7 \pm 12.1$ & $10.5 \pm 9.9$ & 0.67 \\
\hline Baseline oxygen saturation level (\%) & $96.0 \pm 1.8$ & $96.7 \pm 1.6$ & $0.01^{*}$ \\
\hline Minimum oxygen saturation level (\%) & $83.6 \pm 6.7$ & $88.4 \pm 4.6$ & $0.01^{*}$ \\
\hline $4 \% \mathrm{ODI}(\mathrm{h})$ & $25.0 \pm 16.7$ & $7.41 \pm 7.65$ & $0.01^{*}$ \\
\hline Modified CT90\% & $4.7 \pm 9.2$ & $0.5 \pm 1.1$ & $0.01^{*}$ \\
\hline Average time used for ASV (h) & & $5.9 \pm 2.7$ & \\
\hline
\end{tabular}

Data given as mean \pm SD. ${ }^{*} \mathrm{p}<0.05$.

ASV, adaptive servo-ventilation.

BNP, brain natriuretic peptide; LVEF, left ventricular ejection fraction;

NREM, nonrapid eye movement; REM, rapid eye movement; ODI, oxygen desaturation index; СT90\%, cumulative percentage of time at a pulse-oxymetry oxygen saturation below $90 \%$.

In non-responders (Table 4), after ASV therapy, significant improvements were observed with respect to AHI (before ASV therapy, $49.9 \pm 33.2 / \mathrm{h}$; after ASV therapy, $9.2 \pm 9.1 / \mathrm{h} ; P=0.01$ ), CSA index, OSA index, minimum oxygen saturation level, and 4\%ODI but not with respect to NYHA classification, LVEF (before ASV therapy,
49.3\% \pm 15.0\%; after ASV therapy, 50.2\% \pm $17.5 \% ; P=0.88$ ), mixed AI, HI, sleep efficiency, baseline oxygen saturation level, and modified CT90\% (before ASV therapy, $3.7 \% \pm 6.0 \%$; after ASV therapy, $1.8 \% \pm$ $2.9 \% ; P=0.34)$. Drug therapy did not change before and after ASV therapy. 


\begin{tabular}{|c|c|c|c|}
\hline & Before ASV therapy & After ASV therapy & P value \\
\hline$B N P(p g / m L)$ & $412.5 \pm 622.2$ & $642.2 \pm 954.5$ & $0.04^{*}$ \\
\hline NYHAIII IV(\%) & $10(47.6)$ & $9(42.9)$ & 0.99 \\
\hline $\operatorname{LVEF}(\%)$ & $49.3 \pm 15.0$ & $50.2 \pm 17.5$ & 0.34 \\
\hline Arterial $\mathrm{O}_{2}$ tension $(\mathrm{mmHg})$ & $94.5 \pm 25.7$ & $89.9 \pm 9.5$ & 0.47 \\
\hline Arterial $\mathrm{CO}_{2}$ tension $(\mathrm{mmHg})$ & $37.5 \pm 5.0$ & $42.4 \pm 5.3$ & 0.45 \\
\hline Apnea hypopnea index $(/ \mathrm{h})$ & $32.2 \pm 16.7$ & $10.7 \pm 9.1$ & $0.01^{*}$ \\
\hline Central sleep apnea index $(/ \mathrm{h})$ & $6.1 \pm 8.6$ & $0.4 \pm 0.8$ & $0.01^{*}$ \\
\hline Obstructive sleep apnea index $(/ \mathrm{h})$ & $7.9 \pm 11.1$ & $1.8 \pm 3.0$ & $0.04^{*}$ \\
\hline Mixed apnea index $(/ \mathrm{h})$ & $3.6 \pm 6.7$ & $0.2 \pm 0.6$ & 0.05 \\
\hline Hypopnea index $(/ \mathrm{h})$ & $14.7 \pm 11.1$ & $8.2 \pm 9.3$ & 0.15 \\
\hline Sleep efficiciecy $(\%)$ & $38.2 \pm 18.3$ & $34.6 \pm 33.9$ & 0.88 \\
\hline NREM stage I (\%) & $40.7 \pm 27.8$ & $49.4 \pm 46.6$ & 0.80 \\
\hline NREM stage II (\%) & $48.7 \pm 27.8$ & $39.7 \pm 40.4$ & 0.95 \\
\hline NREM stage III (\%) & $5.2 \pm 8.4$ & $6.2 \pm 8.1$ & 0.24 \\
\hline NREM stage IV $(\%)$ & $0.3 \pm 0.8$ & $1.9 \pm 2.6$ & 0.41 \\
\hline REM(\%) & $5.0 \pm 6.2$ & $4.3 \pm 8.6$ & 0.76 \\
\hline Baseline oxygen saturation level (\%) & $96.1 \pm 1.9$ & $96.1 \pm 1.6$ & 0.09 \\
\hline Minimum oxygen saturation level (\%) & $84.9 \pm 6.0$ & $86.7 \pm 8.4$ & $0.01^{*}$ \\
\hline $4 \% \mathrm{ODI}(\mathrm{h})$ & $23.5 \pm 17.5$ & $11.3 \pm 9.60$ & $0.01^{*}$ \\
\hline Modified CT90\% & $3.7 \pm 6.0$ & $1.8 \pm 2.9$ & 0.06 \\
\hline Average time used for ASV (h) & & $4.6 \pm 3.4$ & \\
\hline
\end{tabular}

Data given as mean $\pm S D$. ${ }^{*} p<0.05$.

ASV, adaptive servo-ventilation.

BNP, brain natriuretic peptide; LVEF, left ventricular ejection fraction;

NREM, nonrapid eye movement; REM, rapid eye movement; ODI, oxygen desaturation index;

CT $90 \%$, cumulative percentage of time at a pulse-oxymetry oxygen saturation below $90 \%$.

In the comparison between responder with non-responder groups after ASV therapy (Figure 1), significant differences were observed with respect to modified CT90\% (responders, $0.5 \% \pm 1.1 \%$; nonresponders, $1.8 \% \pm 2.9 \% ; P=0.01$ ). Responders tend to be longer average time used for ASV therapy(responders, $\quad 5.9 \pm \quad 2.7 \mathrm{~h}$; nonresponders, $4.6 \pm 3.4 \mathrm{~h} ; P=0.15$ ), lower AHI (responders, $6.2 \pm 6.6 / \mathrm{h}$; nonresponders, $10.7 \pm 9.1 / \mathrm{h} ; P=0.06$ ), lower CSA index, lower 4\%ODI. We detected no significant differences with respect to blood gas analysis, LVEF (responders, $\quad 46.9 \% \pm \quad \pm \quad 15.8 \%$; nonresponders, $50.2 \% \pm 17.5 \%$; $P=0.48$ ), OSA index, mixed AI, HI, baseline oxygen saturation level, minimum oxygen saturation level. 

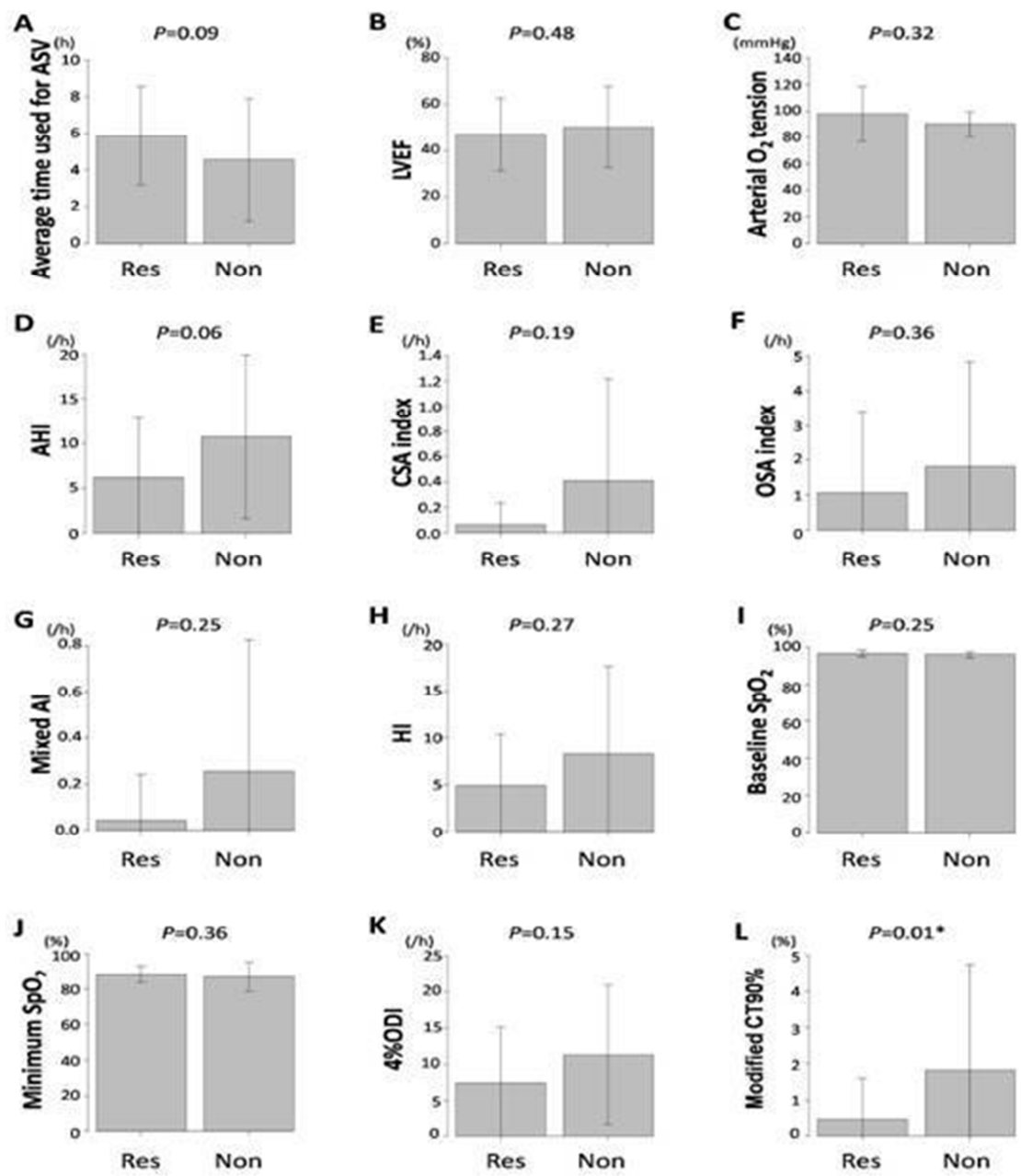

Figure 1. Res, responders; Non, nonresponders.

After ASV (Adaptive servo-ventilation) therapy, no significant differences were observed between responder and nonresponder with respect to (A) average time used for ASV, (B) LVEF (left ventricular ejection fraction), (C) arterial O2 tension, (D) AHI (apnea hypopnea index), (E) CSA (central sleep apnea) index, (F) OSA (obstructive sleep apnea) index, (G) mixed Al (apnea index), (H) $\mathrm{HI}$,. (I) baseline $\mathrm{SpO} 2$, (J) minimum SpO2, (K) $4 \% \mathrm{ODI}$ (oxygen desaturation index), significant differences were observed between responder and nonresponder with respect to $(L)$ modified CT90\% (cumulative percentage of time at a pulse-oxymetry oxygen saturation below $90 \%$ ). $*$ p<0.05

Only modified CT90\% value showed difference between two groups after ASV therapy. We defined normal criteria of modified CT90\% as <1, and performed logistic regression analysis (Table 5). With regard to the evaluation of oxygenation, "Minimum oxygen saturation level" and "4\%ODI" were the similar parameter as "modified CT90\%". "Average time used for ASV therapy" and "AHI" tended to be different between responders and nonresponders with lower $\mathrm{p}$ value (Figure 1). "LVEF" significantly improved after ASV therapy in responders (Table 3). These 6 parameters were compared between responder group and nonresponder group. Univariate analysis demonstrated that improvement of modified CT $90 \%<1$ was significantly different between two groups. Multivariate analysis revealed that improvement of modified CT $90 \%<1$ was independent factor for the responder group. The adjusted odds ratio was 7.48 (95\% confident interval $1.22-45.8, P=$ 0.029). 


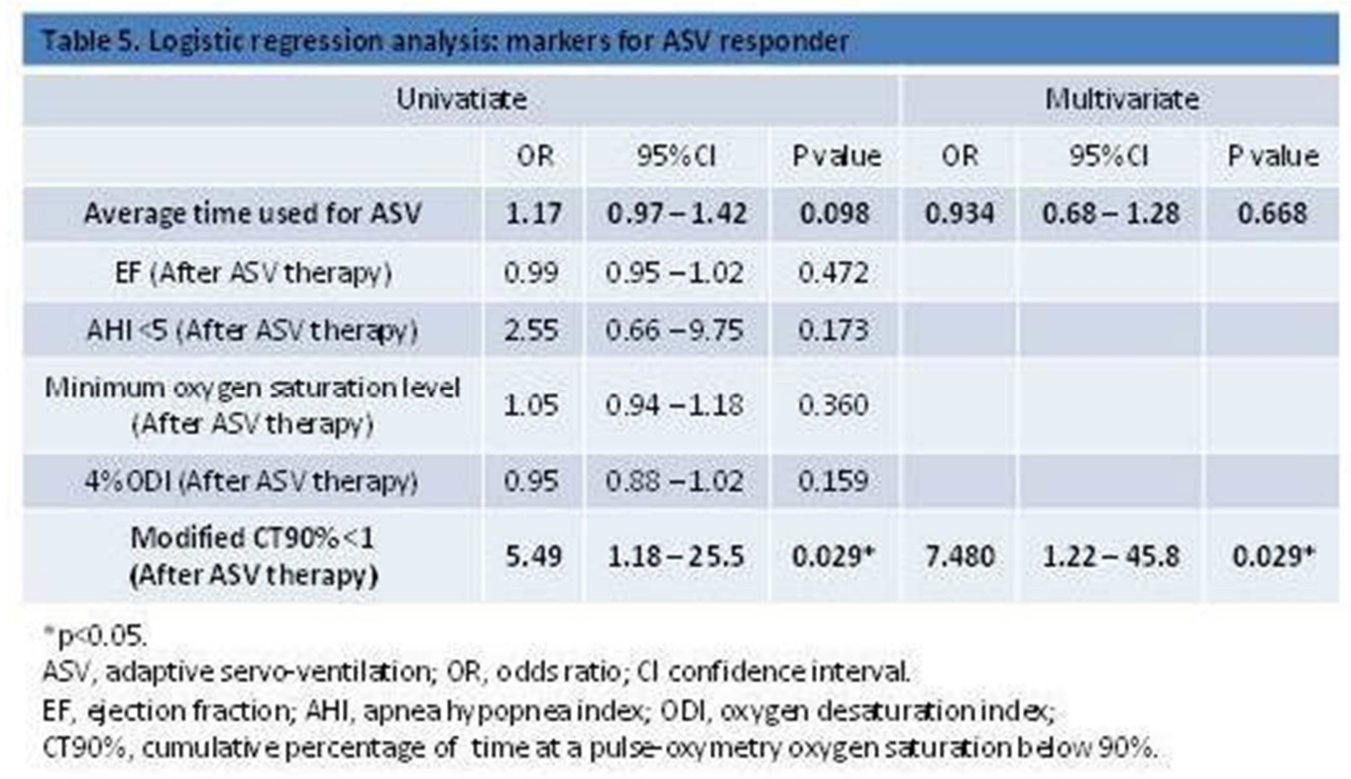

\section{Discussion}

In this study, we analyzed ASV therapy data of HF patients to identify reliable factors indicateve of a positive response to ASV. Our results show that improvement in oxygen saturation levels is associated with positive response to ASV.

Until recently, the results of several studies had suggested that continuous positive airway pressure (CPAP) therapy is effective for treating not only OSA but also HF (Sin et al., 2000) (Arzt et al., 2007) (Egea et al., 2008). However CPAP therapy does not improve the prognosis for all patients. In HF patients, CPAP mainly elevates intrathoracic pressure which reduces the venous return and preload, but CPAP therapy does not treat CSR directly. CPAP nonresponders should upgrade to ASV therapy, which effectively treats coexisting CSA and CSR in HF patients as well as other types of SDB, including OSA and complex sleep apnea syndrome, because ASV therapy provides suitable ventilator support using expiratory positive airway pressure and a pressure support system (Alam et al., 2007) (Khayat et al., 2010) (Hastings et al., 2010). However, prognosis was not improved for all patients after ASV therapy. Some patients showed improved $\mathrm{AHI}$, but did not show improvement in BNP levels. Here we defined ASV responders as patients whose BNP level decreased after ASV therapy.

In our study, responder group significantly improved NYHA classification, whereas nonresponder group did not. This clinical parameter suggested the validity of our definition of responders and nonresponders. At baseline, responders tended to be younger and have lower EF, a higher percentage of cardiomyopathy and rapid-eye-movement sleep compared with nonresponders, but the difference was not statistically significant. Characteristics of responders before and after ASV therapy showed significant improvements in LVEF, AHI, CSA index, OSA index, mixed AI, HI, baseline oxygen saturation level, minimum oxygen saturation level, 4\% ODI and modified CT90\%. In nonresponder group, on the other hand, there were no significant differences between before and after ASV therapy in the values of LVEF, mixed AI, HI and baseline oxygen saturation level. It is worth stressing that among various parameters indicating the significant improvement after ASV therapy in both responders and nonresponders, there was significant difference between responders and nonresponders in the value of modified CT $90 \%$. The modified CT $90 \%$ was determined to be $0.5 \% \pm 1.1 \%$ in responders and $1.8 \% \pm 2.9 \%$ in nonresponders after ASV therapy $(\mathrm{p}=0.01)$. 
Although these values are approximately equal to $1 \%$, improvement of modified CT $90 \%<1$ could be used to evaluate responders to ASV therapy.

What are the potential mechanisms by which modified CT90\% is associated with the response to ASV therapy? It has been acknowledged by CANPAP study (Bradley et al., 2005) and its post hoc analysis that an increase in nocturnal oxygen saturation is a major determinant for improvement of daytime left ventricular ejection fraction despite the optimal titration of CPAP therapy (Arzt et al., 2007). It is likely that ASV therapy can increase intrathoracic pressure but cannot necessarily improve every aspect of SDB such as sleep efficiency and spontaneous arousals in all patients with HF even though ASV significantly reduces $\mathrm{AHI}$ and CSR. In this regard, we assume that modified CT $90 \%$ as measured by PSG in this study is the most sensitive to oxygenation during sleep and this value may reflect the underlying severity of the SDB, which may be attributed to enhanced chemosensitivity of central and peripheral receptors and to activation of pulmonary irritant receptors caused by pulmonary congestion. Nocturnal transient hypoxia is known to activate sympathetic nervous system, and which may result in poor response to ASV therapy in HF patients. It is possible that improvement of modified CT90\% suggest improvement of pulmonary congestion. Further studies to test our hypothesis should be warranted.

We named percent sleep time of oxygen saturation level below 90\% "Modified CT90\%". The normal range of CT90\% is defined as $<1$. SDB can be screened effectively by in-home measurements of CT90\% using type 3 or type 4 devices (Olson et al., 1999) (Cheson et al., 2007). Modified CT90\% is more accurate parameter than CT90\%, because it is evaluated by PSG. In this study we defined the normal range of modified CT $90 \%<1$ which is the same normal range as CT $90 \%$. Our findings that improvement of modified CT90\% $<1$ is associated with response to ASV therapy support the notion that persistent oxygenation during sleep is important for better clinical outcome, and provide the rationale for future prospective study testing the clinical impact of measuring modified CT90\% in PSG.

\section{Study Limitations}

Selection bias was a major concern, because this study was a single-center study. We included all patients with $\mathrm{HF}$ with NYHA class II-IV to minimize potential selection bias. The most important limitation of the study was the small number of patients, particularly nonresponders; thus, standard deviations became quite large. Some patients had already been administered $\beta$-blockers before the study; although no significant difference was observed between responders and nonresponders, this might have created a bias. We defined responders and nonresponders based on BNP levels after 3 months of ASV therapy. A longer prospective study must be conducted to evaluate the long-term prognosis of responders and nonresponders.

\section{Conclusions}

Despite the demonstrated clinical benefits of ASV therapy in HF patients, $20.3 \%$ of patients failed to show improvement in HF. Our results suggest that favorable response to ASV therapy is associated with improvement of modified CT90\%<1 after 3 months of ASV therapy in HF patients.

\section{Conflict of Interest}

The authors state no conflict of interest.

\section{Abbreviations list}

Adaptive servo-ventilation (ASV)

Central sleep apnea (CSA)

Sleep-disordered breathing (SDB)

Heart failure (HF)

Obstructive sleep apnea (OSA)

Cheyne-Stokes respiration (CSR)

New York Heart Association (NYHA) 
Polysomnography (PSG)

Brain natriuretic peptide (BNP)

Dumulative percentage of time at a pulseoximetry oxygen saturation < $90 \%$ (CT90\%)

Apnea-hypopnea index (AHI)

Left ventricular ejection fraction (LVEF)

Apnea index (AI)

Hypopnea index (HI)

Oxygen desaturation index at the $4 \%$ level (4\%ODI)

Continuous positive airway pressure (CPAP)

\section{References}

Alam, J. S., Olson, E. J., Gay, P. C. \& Morgenthaler, T. I. (2007). "Efficacy of Adaptive Servo-Ventilation in Treatment of Complex and Central Sleep Apnea Syndromes," Chest, 132 (6) 1839-1846.

Arzt, M., Floras, J. S., Logan, A. G., Kimoff, R. J., Series, F., Morrison, D., Ferguson, K., Belenkie, I., Pfeifer, M., Fleetham, J., Hanly, P., Smilovitch, M., Ryan, C., Tomlinson, G. \& Bradley, T. D. (2007). "Suppression of Central Sleep Apnea by Continuous Positive Airway Pressure and Transplant-Free Survival in Heart Failure: A Post Hoc Analysis of the Canadian Continuous Positive Airway Pressure for Patients with Central Sleep Apnea and Heart Failure Trial (CANPAP)," Circulation, 115 (25) 31733180.

Arzt, M., Wensel, R., Montalvan, S., Schichtl, T., Schroll, S., Budweiser, S., Blumberg, F. C., Riegger, G. A. \& Pfeifer, M. (2008). "Effects of Dynamic Bilevel Positive Airway Pressure Support on Central Sleep Apnea in Men with Heart Failure," Chest, 134 (1) 6166.

Ben-Dov, I. Z., Kark, J. D., Ben-Ishay, D., Mekler, J., Ben-Arie, L. \& Bursztyn, M. (2007). "Predictors of All-Cause Mortality in Clinical Ambulatory Monitoring: Unique Aspects of Blood Pressure during Sleep," Hypertension, 49 (6) 1235-1241.

Bradley, T. D., Vazir, A., Meadows, G. E., Dayer, M., Poole-Wilson, P. A., Mcintyre, H. F., Morrell, M. J., Cowie, M. R. \& Simonds, A. K. (2005). "Continuous Positive Airway Pressure for Central Sleep Apnea and Heart Failure," The New England Journal of Medicine, 353 (19) 2025-2033.

Cheson, A. L. Jr., Berry, R. B. \& Pack, A. (2003). "Practice Parameters for the Use of Portable Monitoring Devices in the Investigation of Suspected Obstructive Sleep Apnea in Adults," American Academy of Sleep Medicine: American Thoracic Society: American College of Chest Physicians. Sleep, 26 (7) 907-913.

Clerico, A. \& Emdin, M. (2004). "Diagnostic Accuracy and Prognostic Relevance of the Measurement of Cardiac Natriuretic Peptides: A Review," Clinical Chemistry, 50 (1) 33-50.

Doust, J. A., Pietrzak, E., Dobson, A. \& Glasziou, P. (2005). "How Well Does B-Type Natriuretic Peptide Predict Death and Cardiac Events in Patients with Heart Failure: Systematic Review," BMJ: British Medical Journal, 330 (7492) 625.

Egea, C. J., Aizpuru, F., Pinto, J. A., Ayuela, J. M., Ballester, E., Zamarrón, C., Sojo, A., Montserrat, J. M., Barbe, F., Alonso-Gomez, A. M., Rubio, R., Lobo, J. L., Duran-Cantolla, J., Zorrilla, V., Nu-ez, R., Cortés, J., Jiménez, A., Cifrián, J., Ortega, M., Carpizo, R., Sánchez, A., Terán, J., Iglesias, L., Fernández, C., Alonso, M. L., Cordero, J., Roig, E., Pérez, F., Muxi, A., Gude, F., Amaro, A., Calvo, U., Masa, J. F., Utrabo, I., Porras, Y., Lanchas, I. \& Sánchez, E. (2008). "Cardiac Function after CPAP Therapy in Patients with Chronic Heart Failure and Sleep Apnea: A Multicenter Study," Sleep Medicine, 9 (6) 660-666.

Hastings, P. C., Vazir, A., Meadows, G. E., Dayer, M., Poole-Wilson, P. A., Mcintyre, H. F., Morrell, M. J., Cowie, M. R. \& Simonds, A. K. (2010). "Adaptive Servo-Ventilation in Heart Failure Patients with Sleep Apnea: A 
Real World Study," International Journal of Cardiology, 139 (1) 17-24.

Javaheri, S., Parker, T. J., Liming, J. D., Corbett, W. S., Nishiyama, H., Wexler, L. \& Roselle, G. A. (1998). "Sleep Apnea in 81 Ambulatory Male Patients with Stable Heart Failure: Types and Their Prevalence, Consequence, and Presentations," Circulation, 97 (21) 2154-2159.

Kasai, T., Narui, K., Dohi, T., Takaya, H., Yanagisawa, N., Dungan, G., Ishiwata, S., Ohno, M., Ymaguchi, T. \& Momomura, S. (2006). "First Experience of Using New Adaptive Servo-Ventilation Device for Cheyne-Stokes Respiration with Central Sleep Apnea among Japanese Patients with Congestive Heart Failure: Report of 4 Clinical Cases," Circulation Journal: Official Journal of the Japanese Circulation Society, 70 (9) 1148-1154.

Kato, M., Adachi, T., Koshino, Y. \& Somers, V. K. (2009). "Obstructive Sleep Apnea and Cardiovascular Disease," Circulation Journal: Official Journal of the Japanese Circulation Society, 73 (8) 1363-1370.

Khayat, R. N., Abraham, W. T., Patt, B., Roy, M., Hua, K. \& Jarjoura, D. (2010). 'Cardiac Effects of Continuous and Bilevel Positive Airway Pressure for Patients with Heart Failure and Obstructive Sleep Apnea: A Real World Study,' International Journal of Cardiology, 139 (1) 17-24.

Moruzzi, P., Sarzi-Braga, S., Rossi M. \& Contini, M. (1999). "Sleep Apnea in Ischemic Heart Disease: Difference between Acute and Chronic Coronary Syndromes," Heart, 82 (3) 343-347.

Olson, L. G., Ambrogetti, A. \& Gyulay, S. G. (1999). "Prediction of Sleep-Disordered Breathing by Unattended Overnight Oximetry," Journal of Sleep Research, 8 (1) 51-55.

Pepperll, J. C., Maskell, N. A., Jones, D. R., Langford-Wiley, B. A., Crosthwaite, N., Strading, J. R. \& Davies, R. J. (2003). "A Randomized Control Trial of Adaptive Ventilation of Cheyne-Stokes Breathing in Heart Failure," American Journal of
Respiratory and Critical Care Medicine, 168 (9) 1109-1114.

Serizawa, N., Yumiko, D., Kajimoto, K., Tagawa, Y., Takagi, A., Shoda, M., Kasanuki, H. \& Hagiwara, N. (2008). "Impact of SleepDisordered Breathing on Life-Threatning Ventricular Arrhythmia in Heart Failure Patients with Implantable CardioverterDefibrillator," The American Journal of Cardiology, 102 (8) 1064-1068.

Sin, D. D., Logan, A. G., Fitzgerald, F. S., Liu, P. P. \& Bradley, T. D. (2000). "Effects of Continuous Positive Airway Pressure on Cardiovascular Outcomes in Heart Failure Patients with and without Cheyne-Stokes Respiration," Circulation, 102 (1) 61-66.

Somers, V. K., White, D. P., Amin, R., Abraham, W. T., Costa, F., Culebras, A., Daniels, S., Floras, J. S., Hunt, C. E. et al. (2008). "Sleep Apnea and Cardiovascular Disease: An American Heart Association/ American College of Cardiology Foundation Scientific Statement from the American Heart Association Council for High Blood Pressure Research Professional Education Committee, Council on Clinical Cardiology, Stroke Council, and Council on Cardiovascular Nursing," Journal of the American College of Cardiology, 52 (8) 686717.

Takama, N. \& Kurabayashi, M. (2007). "Possibility of Close Relationship between Sleep Disorder Breathing and Acute Coronary Syndrome," Journal of Cardiology, 49 (4) 171-177.

Takama, N. \& Kurabayashi, M. (2009). "Influence of Untreated Sleep-Disordered Breathing on the Long-Term Prognosis of Patients with Cardiovascular Disease," The American Journal of Cardiology, 49 (5) 1625-1631.

Takama, N. \& Kurabayashi, M. (2011). "Effectiveness of Adaptive ServoVentilation for Treating Heart Failure Regardless of the Severity of SleepDiordered Breathing," Circulation Journal: Official Journal of the Japanese Circulation Society, 75 (5) 1164-1169. 
Takama, N. \& Kurabayashi, M. (2012). "Effect of Adaptive Servo-Ventilation on 1Year Prognosis in Heart Failure Patients," Circulation Journal: Official Journal of the Japanese Circulation Society, 76 (3) 661-667.

Teschler, H., Döhring, J., Wang, Y. M. \& Berthon-Jones, M. (2001). "Adaptive Pressure Support Servo-Ventilation: A Novel Treatment for Cheyne-Stokes Respiration in Heart Failure," American Journal of Respiratory and Critical Care Medicine, 164 (4) 614-619.
Wang, H., Parker, J. D., Newton, G. E., Floras, J. S., Mak, S., Chiu, K. L., Ruttanaumpawan, P., Tomlinson, G. \& Bradley, T. D. (2007). "Influence of Obstructive Sleep Apnea on Mortality in Patients with Heart Failure," Journal of the American College of Cardiology, 49 (15) 1625-1631. 